ORIGINAL ARTICLE

\title{
Relationship of C-Reactive Proteins and Erythrocyte Sedimentation Rate with Active Disease in Patients with Juvenile Rheumatoid Arthritis
}

\author{
RIFFAT FARRUKH ${ }^{1}$, SHAHEEN MASOOD², AMBER NASEER ${ }^{3}$, QAMAR RIZVI ${ }^{4}$, SARWAT SULTANA ${ }^{5}$, MASROOR H. \\ SHARFI ${ }^{6}$ \\ ${ }^{1}$ Assistant Professor, Department of Pediatrics, Karachi Medical and Dental College/ Abbasi Shaheed Hospital Karachi \\ ${ }^{2}$ Assistant Professor Pediatrics, Karachi Medical and Dental College Karachi \\ ${ }^{3}$ Senior Registrar, Department of Paediatric, Karachi Medical \& Dental College Karachi/ Abbasi Shaheed Hospital, Karachi \\ ${ }^{4}$ Department of Pharmacology, Jinnah Medical and Dental College, Karachi \\ ${ }^{5}$ AssistantProfessor Community Medicine Department, Karachi Medical \& Dental College, Karachi \\ ${ }^{6}$ Assistant Consultant, Department of Pediatrics Cardiology, King Faisal Specialist Hospital and RC, Jeddah, Saudi Arab \\ Corresponding author: Dr. Riffat Farrukh, Email: riffatfarrukh15@gmail.com,Cell No.+92-345-8260400
}

\begin{abstract}
Objective: To determine the relationship between serum C-reactive protein (CRP) and erythrocyte sedimentation rate (ESR) with active disease in patients with juvenile rheumatoid arthritis (JRA).

Methods: This is a cross-sectional analytical study conducted at the Department of Paediatrics, Abbasi Shaheed Hospital, Karachi for one-year duration from April 2020 to April 2021. All patients who met the MJA's American College of Rheumatology (ACR) criteria were enrolled in the study. The ACR 20 improvement criteria were used to define the pardon of the disease, and those who met the ACR20 recovery criteria were included in the remission group. Laboratory tests such as PCR and ESR. Statistical analysis was performed using SAS software (version 10.3).

Results: The study involved 90 patients, including 28 in the remission group (31.2\%) and 62(68.88\%) in the active disease group. There were $61.11 \%(n=55)$ of females, and the ratio of males to females was 3: 4 . The mean age of the subjects was $10.12 \pm 3.39$ years (4-17 years). Distribution of the age of admission by different subgroups, 13 patients (14.44\%) aged 1-5 years, 31 patients (34.44\%) aged 5-10 years, 40 patients (44.44\%) aged $10-15$ years and 6 patients $(6.66 \%)$ were over 15 years old. The mean duration of the disease was $2.40+$ 2.11 years (range $=0.3-7$ years). The onset of the disease in 21 patients $(23.33 \%$ ) lasting one year $(22.9 \%)$ from the onset of the disease, 48 patients (53.33\%) presented one to five years from the onset of the disease, and 21 patients (23.33\%) over five years. The most common type of arthritis was polyarthritis in 43 patients (47.77\%), followed by oligo-arthritis in 31 patients (34.44\%) and systemic onset in 12 patients (13.33\%). The mean ESR was $41.03+27.80 \mathrm{~mm} /$ hour 1 . (Range $=07-128 \mathrm{~mm} /$ hour 1 ) And mean CRP $16.1+13.80 \mathrm{mg} / \mathrm{L}$ (range =6-47 $\mathrm{mg} / \mathrm{L})$. While the ESR was $30 \mathrm{~mm} / 1$ hour in 50 of the 90 patients (55.55\%), 43 of these 50 patients (86\%) were in the active disease group. Similarly, positive CRP was found in 58 patients (64.44\%), of whom 52 (89.7\%) belonged to the group with active disease. Compared with the remission and active disease groups, 33 patients of active diseases were female. In the active disease group, the mean age was $11.01+3.30$ years, and the duration of the disease began at one year in patients. Polyarthritis was detected in $26 / 62(41.9 \%)$ of patients in the active disease group.

Conclusion: High CRP and ESR parameters are good for predicting active disease in JRA patients. Keywords: C-reactive protein, Juvenile rheumatoid arthritis, JRA and Erythrocyte mentation rate.
\end{abstract}

\section{INTRODUCTION}

Juvenile rheumatoid arthritis (JRA) is a chronic inflammatory disease with different incidences of racial and ethnic subtypes ${ }^{1}$. The incidence of JRA in the 15-year-old white population is $13.9 / 100,000$. JRA is a cause of potential disability, discomfort, and long-term disability, although some patients may experience uneventful remission. Advances in recent treatments appear promising, and early treatment, along with timely rehabilitation, can optimize outcomes ${ }^{2-3}$. Therefore, identifying patients with JRA who are at high risk for adverse events helps select patients for aggressive early treatment. There are many advertisers for the result, but only a few are described as initial advertisers ${ }^{4}$. JRA's laboratory research can be used to provide evidence of inflammation, control treatment toxicity, and better understand the pathogenesis of disease ${ }^{5}$. Useful laboratory tests for JRAs include blood counts (CBC), rheumatoid factor (RF), and inflammatory markers such as red blood cell sedimentation rate (ESR) and C-reactive protein $(\mathrm{CRP})^{6-7}$. Westergren's ESR is the rate at which red blood cells drop in 1 hour. This is a useful but surprising measure of active disease, both in the onset and follow-up of a child with arthritis. Acute phase proteins (APPs) are proteins that increase in plasma levels during acute phase reactions, such as trauma, infection, cancer, overexertion, and rheumatic diseases ${ }^{8}$. The APP contains certain protein supplements, CRP and fibrinogen to help maintain and maintain osteosis ${ }^{9}$. C-reactive protein is an acute phase protein found in the blood, and its levels increase with any inflammation in the body. In the acute phase of response, CRP levels rise significantly and peak within 2 hours and 48 hours of acute trauma. As the acute phase response decreases, CRP decreases with a relatively short half-life of 18 hours $^{10}$. CRP is a more sensitive and accurate reflection of the acute phase response than ESR. During the first 24 hours of the acute phase, the ESR response 
may be normal, but as CRP levels rise before treatment, the CRP tends to return to normal rather than $\mathrm{ESR}^{11}$. This study was conducted to determine the relationship between C-reactive protein (CRP) and erythrocyte sedimentation rate (ESR) and active disease in patients with juvenile rheumatoid arthritis.

\section{METHODS}

This is a cross-sectional analytical study conducted at the Department of Paediatrics, Abbasi Shaheed Hospital, Karachi for one-year duration from April 2020 to April 2021. The official approval of the local ethics committee and the informed consent of all parents were obtained. All male and female patients who met the American College of Rheumatology (ACR) JRA criteria were enrolled in the study. ACR criteria include: Symptoms of one or more arthritis under the age of 16, duration of the disease for 6 weeks or more, type of onset defined in the first 6 months: i. Polyarthritis: When 5 or more joints become inflamed, ii. Oligoarthritis: Less than 5 inflamed joints, iii. Systemic onset: characteristic of febrile arthritis), Excluding other forms of juvenile arthritis. Data collected at the first clinical visit included demographics, time of onset, and type of arthritis recorded in a pre-designed format. ACR 20 treatment criteria were used to determine disease remission. The ACR 20 improvement criteria showed a $20 \%$ improvement in the number of swollen joints and a painful joint scored with 28 or more joints. In addition, 3 out of 5 measurements improved by $20 \%$ : patient pain assessment, overall patient assessment, general physician assessment, self-assessment of patient disability, and acute phase reactant (CRP or ESR). A horizontal visual analog scale (usually $10 \mathrm{~cm}$ ) of the patient's current pain situation and overall assessment of the physician and patient. Patients who met the criteria for ACR20 improvement were in the remission group and the remaining patients had active disease. Laboratory parameters such as erythrocyte sedimentation rate (ESR) and C-reactive protein (CRP) were ordered. A quantitative agglutination method (Human Tex CRP, Wiesbaden, Germany) was used for serum CRP and Westergren ESR analysis for ESR levels. Samples were considered "positive" if CRP was present at a concentration of $6 \mathrm{mg} / \mathrm{L}$ or more. The rise in CSR was greater than $30 \mathrm{~mm}$ in the first hour. Statistical data analysis was performed using the Statistical Analysis System (SAS) of version 10.3. The mean, standard deviation, and range were determined for all quantitative variables. Baseline frequencies and percentages, age and gender distribution, and duration of disease were used to identify and determine active disease groups and types of arthritis. Binary logistic regression was used to determine age and initial disease duration and the active disease group and the relationship between ESR and CRP. A value of $P<0.05$ was considered statistically significant.

\section{RESULTS}

The study involved 90 patients, including 28 in the remission group (31.2\%) and $62(68.88 \%)$ in the active disease group. There were $61.11 \%(n=55)$ of females, and the ratio of males to females was $3: 4$. The mean age of the subjects was $10.12 \pm 3.39$ years (4-17 years). Distribution of the age of admission by different subgroups, 13 patients (14.44\%) aged $1-5$ years, 31 patients $(34.44 \%)$ aged $5-10$ years, 40 patients (44.44\%) aged $10-15$ years and 6 patients $(6.66 \%)$ were over 15 years old. The mean duration of the disease was $2.40+2.11$ years (range $=$ $0.3-7$ years).

Distribution of Patients given in Table-I
\begin{tabular}{|l|l|}
\hline Males & $35(38.9 \%)$ \\
\hline Females & $5561.11 \%$ \\
\hline Total & $90(100 \%)$ \\
\hline Active disease patients' group & $62(68.88 \%)$ \\
\hline remission group & $28(31.2 \%)$ \\
\hline Mean age & $10.12 \pm 3.39$ years $(4-17$ \\
& years $)$ \\
\hline Age group & \\
\hline $1-5$ years & $13(14.44 \%)$ \\
\hline $5-10$ years & $31(34.44 \%)$ \\
\hline $10-15$ years & $40(44.44 \%)$ \\
\hline over 15 years & $6(6.66 \%)$ \\
\hline Mean duration of the disease & $2.40+2.11$ years (range $=$ \\
& $0.3-7$ years). \\
\hline Type of arthritis & \\
\hline polyarthritis & $43(47.77 \%)$ \\
\hline oligo-arthritis & $31(34.44 \%)$ \\
\hline systemic onset & $12(13.33 \%)$ \\
\hline
\end{tabular}

The onset of the disease in 21 patients $(23.33 \%)$ lasting one year (22.9\%) from the onset of the disease, 48 patients $(53.33 \%)$ presented one to five years from the onset of the disease, and 21 patients (23.33\%) over five years. The most common type of arthritis was polyarthritis in 43 patients (47.77\%), followed by oligo-arthritis in 31 patients (34.44\%) and systemic onset in 12 patients (13.33\%). The mean ESR was $41.03+27.80 \mathrm{~mm} /$ hour 1 . (Range $=07-128 \mathrm{~mm} /$ hour 1) And mean CRP $16.1+$ $13.80 \mathrm{mg} / \mathrm{L}$ (range $=6-47 \mathrm{mg} / \mathrm{L}$ ). While the ESR was $>30$ $\mathrm{mm} / 1$ hour in 50 of the 90 patients $(55.55 \%), 43$ of these 50 patients $(86 \%)$ were in the active disease group. Similarly, positive CRP was found in 58 patients $(64.44 \%)$, of whom $52(89.7 \%)$ belonged to the group with active disease. Compared with the remission and active disease groups, 33 patients of active diseases were female. In the active disease group, the mean age was $11.01+3.30$ years, and the duration of the disease began at one year in patients. Polyarthritis was detected in $26 / 62$ (41.9\%) of patients in the active disease group.

The comparison of the two groups (Table 2) showed an improvement in all segments of the remission group compared to the group with active disease according to the ACR 20 criteria. Binary logistic regression was used to determine their relationship with the active disease group CRP and ESR. The regression model also initially considered remission, early age, and other quantitative parameters that affect disease duration. Duration of disease at presentation $(p=0.042)$, higher ESR $(p=$ $0.0022)$, and positive CRP $(p=0.0013)$ were associated with active disease on presentation. In this study, the age of presentation was not related to the active disease group (Table 3). 
ACR 20 Improvement Criteria in Active Disease Group and Remission Group shown in Table-II

\begin{tabular}{|c|c|c|c|}
\hline ACR20 Improvement Criteria & Active Disease Group n=62 (Percentage) & $\begin{array}{l}\text { Remission Group } \mathrm{n}=28 \text { ) } \\
\text { (Percentage) }\end{array}$ & $\begin{array}{l}\text { Total } \mathrm{n}=90 \\
\text { (Percentage) }\end{array}$ \\
\hline Swollen joint count & $42(67.7)$ & $17(67.7)$ & $59(65.5)$ \\
\hline 4-8 joints & $12(19.3)$ & $8(28.6)$ & $20(22.2)$ \\
\hline$>8$ joints & $08(12.9)$ & $3(10.7)$ & $11(12.2)$ \\
\hline $\begin{array}{l}\text { Tender joint count } \\
0-4 \text { joints }\end{array}$ & $32(51.6)$ & $20(71.4)$ & $52(57.8)$ \\
\hline 4-8 joints & $16(25.8)$ & $4(14.3)$ & $20(22.2)$ \\
\hline$>8$ joints & $14(22.5)$ & $4(14.3)$ & $18(20)$ \\
\hline $\begin{array}{l}\text { Pain visual analogue scale } \\
\text { Mild pain }(0-3)\end{array}$ & $30(48.4)$ & $25(89.3)$ & $55(61.1)$ \\
\hline Moderate pain (4-6) & $24(38.7)$ & $1(3.6)$ & $25(28.9)$ \\
\hline Severe pain $(>6)$ & $09(14.5)$ & $1(3.6)$ & $10(10.0)$ \\
\hline $\begin{array}{l}\text { Physician's global assessment } \\
\text { Mild }\end{array}$ & 08 (12.9) & $23(82.1)$ & $31(34.4)$ \\
\hline Moderate & $17(27.4)$ & $02(7.1)$ & $19(21.1)$ \\
\hline Severe & $37(59.7)$ & $03(10.8)$ & $40(44.4)$ \\
\hline $\begin{array}{l}\text { Patient's global assessment } \\
\text { Mild }\end{array}$ & 08 (12.9) & $26(92.8)$ & $34(37.8)$ \\
\hline Moderate & $31(50.0)$ & $00(0)$ & $31(34.4)$ \\
\hline Severe & $23(37.1)$ & $1(3.6)$ & $24(26.7)$ \\
\hline${ }^{*} \mathrm{ESR}>30 \mathrm{~mm}$ in $1^{\text {st }}$ hour & $43(86)$ & $06(21.4)$ & $49(54.4)$ \\
\hline${ }^{\star *} \mathrm{CRP}>06 \mathrm{mg} / \mathrm{l}$ & $52(89.7)$ & $05(17.9)$ & $57(63.3)$ \\
\hline
\end{tabular}

Relation of Active disease with various parameters in Juvenile Rheumatoid Arthritis patients shown in Table-III

\begin{tabular}{|l|l|l|l|l|}
\hline Variable & df & Estimated value & t-value & $\mathrm{p}$-value \\
\hline $\begin{array}{l}\text { Age at } \\
\text { presentation }\end{array}$ & 1 & -0.00249 & -0.18 & 0.85 \\
\hline $\begin{array}{l}\text { Duration of } \\
\text { disease at } \\
\text { presentation }\end{array}$ & 1 & -0.04461 & -2.1 & 0.042 \\
\hline${ }^{*}$ ESR & 1 & -0.00512 & -3.12 & 0.0022 \\
\hline${ }^{* *} \mathrm{CRP}$ & 1 & -0.01078 & -3.29 & 0.0013 \\
\hline
\end{tabular}

\section{DISCUSSION}

Juvenile rheumatoid arthritis (JRA) is the most common rheumatic disease in children. Over the last decade, it has been questioned that JRA is a disease that is usually resolved in childhood. Remission usually occurs in the first five years after the onset and is less common in patients with systemic onset and polyarticular JIA. Therefore, JRA is usually a disease that progresses into adulthood ${ }^{12}$. Compared to previous decades, functional outcomes have improved, but the estimated rate of arthroplasty is still very high. This study showed that the late age of acceptance and the gender of women predominate. This is consistent with another study by Lahore ${ }^{13-14}$. In India, old age was also seen in the presentation. The reason may be the ethnic and geographical similarity of the two populations or the biological characteristics of the disease on this subcontinent ${ }^{15}$. The gender dominance of women in the JRA has been described in Western literature and has been picked up in many studies in Sri Lanka and Bangladesh. It is well known that the gender of women is associated with active disease. In this cross-sectional study, $68.8 \%$ of patients had active disease. Bouchr et al. More than $80 \%$ of patients had active disease in adulthood. Studies in India have shown similar results. In this study, the most common type of JRA is polyarticular JRA. Many studies in Lahore, Sri Lanka and India have yielded similar results $^{16-17}$. This is different from the West, where polyarthritis and systemic onset disease are more common than polyarthritis. Moreover, while all the studies in Pakistan, India and Sri Lanka were hospitalized, the studies in Western countries were population-based studies, so comparisons are difficult ${ }^{18}$. Comparing the different subtypes of the active disease group and the remission group, it was found in our study that only one type of disease was not negative. This is because different variables affect different types of outcomes, such as gender, underlying disease duration, and seropositivity. This is consistent with another study by Oen et al. Different subtypes were replaced with different variables. This is Guillaume et al reported that the arthritic group was in remission more often than in other types. Similarly, Aggarwal et al found that $45 \%$ of patients in the nonlinear group and $20 \%$ of patients in the polyarticular group were in remission ${ }^{18-19}$. In our study the majority of the population had late illnesses and this may be a reason for the presentation of all subtypes. This is consistent with research in India that the long duration of the disease is permanently associated with active disease ${ }^{20-21}$. Zak et al. The duration of the disease has also been reported to be the strongest predictor of adverse disease outcomes at onset. CRP and ESR, two known acute-phase reagents, are used clinically in the follow-up of JRA patients. In this study, and in line with other studies, these parameters were increased in patients with active disease and were normal in remission patients ${ }^{22}$. Al-Matar et al. They concluded that the highest ESR value in the first six months of the group with polyarticular involvement was one of the risk factors for patients without linear JRA. Flato et al. The high CSR values had little or no effect on prognosis upon admission to hospital. They also showed that increasing the duration of ESR in the first six months was a risk factor for poor results ${ }^{23-24}$. Several studies have shown that ESR may be a better parameter than CRP levels, but a high baseline CRP level can strongly predict failure of first remission treatment. Zak et al. The diagnosis showed a marked increase in CRP 
in people with active disease ${ }^{26}$. In another study, increased markers of inflammation, including ESR and CRP, along with other factors such as female gender, polyarthritis, and seropositivity, were consistent predictors of poor prognosis.

\section{CONCLUSION}

Juvenile rheumatoid arthritis is a chronic disease that causes long-term disability. Positive CRP and increased ESR are strongly associated with active disease in JRA patients. Late referrals to a pediatric rheumatologist have a poor prognosis in terms of remission of the disease. Early recommendations and strict disease control help to change the course of the disease according to clinical and laboratory parameters.

\section{REFERENCES}

1. Groen-Hakan F, Eurelings L, van Laar J, Rothova A. Relevance of erythrocyte sedimentation rate and C-reactive protein in patients with active uveitis. Graefe's Archive for Clinical and Experimental Ophthalmology. 2019 Jan;257(1):175-80.

2. Wang $H$, Ren $X$, Tan $H$, Wang $Y$. Influence of $A$ Recombinant Human Soluble Tumor Necrosis Factor Receptor FC Fusion Protein on ACR Scale, C-Reactive Protein, Interleukin-6 And Erythrocyte Sedimentation Rate in Children with Juvenile Idiopathic Arthritis. Revista Argentina de ClínicaPsicológica. 2020;29(4):446-53.

3. Hameed AK, El-Said TO, Askar HY, ElKady BA. Performance of serum adenosine deaminase in measuring disease activity in rheumatoid arthritis patients. The Egyptian Rheumatologist. 2019 Apr 1;41(2):81-5.

4. Rodrigues WD, Sarni RO, Fonseca FL, Araújo A, Len CA, Terreri MT. Biomarkers of lipid metabolism in patients with juvenile idiopathic arthritis: relationship with disease subtype and inflammatory activity. Pediatric Rheumatology. 2021 Dec;19(1):1-7.

5. Dev S, Singh A. Study of role of serum amyloid A (SAA) as a marker of disease activity in juvenile idiopathic arthritis. Journal of family medicine and primary care. 2019 Jun;8(6):2129.

6. Marushko T, Holubovska Y, Kulchytska YE. Evaluation of serum calprotectin (MRP-8/MRP-14) levels in patients with juvenile idiopathic arthritis. Journal of Pediatric and Neonatal Individualized Medicine (JPNIM). 2021 Mar 20;10(1):e100140-.

7. Leong KP, Tan JW, Gao X, Koh ET, TTSH Rheumatoid Arthritis Study Group. Conversion among the 28-joint count activity indices for rheumatoid arthritis. European journal of rheumatology. $2020 \mathrm{Jul} ; 7(3): 105$.

8. Sun Y, Wang Z, Chi H, Hu Q, Ye J, Liu H, Cheng X, Shi H, Zhou Z, Teng J, Yang C. Elevated serum levels of interleukin-10 in adult-onset Still's disease are associated with disease activity. Clinical rheumatology. 2019 Nov;38(11):3205-10.

9. Trachtman R, Murray E, Wang CM, Szymonifka J, Toussi SS, Walters H, Nellis ME, Onel KB, Mandl LA. Procalcitonin Differs in Children With Infection and Children With Disease Flares in Juvenile Idiopathic Arthritis. JCR: Journal of Clinical Rheumatology. 2021 Apr 1;27(3):87-91.

10. Eatemadi A, Al Madhani A, Al Maqbali A, Moradzadegan $\mathrm{H}$. Dynamics of Erythrocyte Sedimentation Rate vs. C-reactive protein: Peas in a Pod or Chalk and Cheese?. Renal failure.;26:28.
11. Peng Y, Liu X, Duan Z, Duan J, Zhou Y. The Association of Serum IL-10 Levels with the Disease Activity in SystemicOnset Juvenile Idiopathic Arthritis Patients. Mediators of inflammation. 2021 Mar 22;2021.

12. Bastida C, Soy D, Ruiz-Esquide V, Sanmartí R, Huitema AD. Exposure-response modeling of tocilizumab in rheumatoid arthritis using continuous composite measures and their individual components. British journal of clinical pharmacology. 2019 Aug;85(8):1710-8.

13. Soysal E, Ulutaş F, Tepeli E, Kaymaz S, Çobankara V. IL23R gene polymorphisms in rheumatoid arthritis. Rheumatology International. 2021 May 12:1-8.

14. Rodrigues WD, Sarni RO, Fonseca FL, Araujo A, Len CA, Terreri MT. Biomarkers of lipid metabolism in patients with juvenile idiopathic arthritis: relationship with subtype and inflammatory activity.

15. Aldwin CM, Nath R. Erythrocyte Sedimentation Rate as a Biomarker for Stress and Aging Research. InOxford Research Encyclopedia of Psychology 2019 Jan 25.

16. Khorshidi-Sedehi S, Aryaeian N, Shahram F, Akhlaghi M, Mahmoudi M, Motevalian M, Asgari-Taee F, Hosseini A. Effects of hydroalcoholic extract of Berberisintegerrima on the clinical signs, hs-CRP, TNFa, and ESR in active rheumatoid arthritis patients. Journal of Herbal Medicine. 2021 Aug 1;28:100444.

17. Huang YH, Hu YC, Liao CH, Chiang BL, Lu CH, Li KJ, Yang $\mathrm{YH}$. A single indicator joint in non-systemic juvenile idiopathic arthritis whose ultrasound scores are correlated with disease activity.

18. Winsz-Szczotka K, Kuźnik-Trocha K, Gruenpeter A, Wojdas M, Dąbkowska K, Olczyk K. Association of Circulating COMP and YKL-40 as Markers of Metabolic Changes of Cartilage with Adipocytokines in Juvenile Idiopathic Arthritis. Metabolites. 2020 Feb;10(2):61.

19. Wulandari D, Barlianto W, Sari TL. Low Level of Vitamin D is Correlated with High C-Reactive Protein (CRP) and Disease Activity in Indonesian Juvenile Idiopathic Arthritis (JIA) Patients. The Indonesian Biomedical Journal. 2020 Jun 29;12(2):149-56.

20. Ozisler C, Sandikci SC. Evaluation of red blood cell distribution width in patients with psoriatic arthritis. The Egyptian Rheumatologist. 2020 Oct 1;42(4):309-12.

21. Chen S, Luan H, He J, Wang Y, Zeng X, Li Y, Yuan H. Serum C1q concentration is associated with disease activity in Chinese Takayasu arteritis patients: A case-control study. Health Science Reports. 2021 Jun;4(2):e252.

22. Xue L, Li M, Tao L, Li X, Wang W, Wang Y, Wang B, Zhang Y, Gao N, Dong Y, Zhou T. Plasma Fibrinogen, D-dimer, and Fibrin Degradation Product as Biomarkers of Rheumatoid Arthritis.

23. Tronconi E, Aljaberi N, Merritt A, Grom A, Schulert G, Huggins J, Henrickson M, Brunner H. AB1065 THE UTILISATION OF S100 PROTEINS TESTING IN PEDIATRIC RHEUMATOLOGY PATIENTS IN A TERTIARY CARE INSTITUTION AND IMPLICATIONS FOR CARE.

24. Winsz-Szczotka K, Kuźnik-Trocha K, Lachór-Motyka I, Lemski W, Olczyk K. Concerted Actions by PIICP, CTXII, and TNF- $\alpha$ in Patients with Juvenile Idiopathic Arthritis. Biomolecules. 2021 May; 11(5):648.

25. La C, Lê PQ, Ferster A, Goffin L, Spruyt D, Lauwerys B, Durez P, Boulanger C, Sokolova T, Rasschaert J, Badot V. Serum Calprotectin (S100A8/A9): A Promising Biomarker in Diagnosis and Follow-up in Different Subgroups of Juvenile Idiopathic Arthritis. 